\section{ECONOMICS}

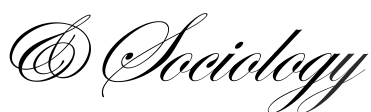

\title{
JOB SATISFACTION OF TEACHERS FROM PUBLIC AND PRIVATE SECTOR UNIVERSITIES IN LAHORE, PAKISTAN: A COMPARATIVE STUDY
}

\author{
Fatima Hameed, \\ University of Labore \\ Labore, Pakistan, \\ E-mail:fatisheikh83@gmail.com \\ Iftikhar Ahmed-Baig, \\ University of Lahore \\ Labore, Pakistan, \\ E-mail: \\ iftikhar.ahmad@ed.uol.edu.pk \\ María Luz Cacheiro- \\ González, \\ Universidad Nacional de Educación \\ a Distancia (UNED) \\ Madrid, Spain, \\ E-mail: \\ mlcacheiro@edu.uned.es
}

Received: March, 2018

1st Revision: March, 2018

Accepted: June, 2018

DOI: $10.14254 / 2071-$

789X.2018/11-4/15

JEL Classification: I23, J28

\begin{abstract}
The purpose of this paper is to analyze the Job Satisfaction of teachers in Higher Education Institutions from the Public and Private Sector in Lahore, Punjab, Pakistan. A comparative study has been carried out, based on the survey method using a quantitative approach. Data were collected from a questionnaire completed by 345 Teachers (203 from public and 142 from private sector), from 10 universities (5 public and 5 private), using convenience sampling. The results of the Chi-Squared independence hypothesis test reveal statistically significant differences in degree of agreement for some of the statements between the Public and Private University Teachers on the Job Satisfaction scale (salary, promotion, benefits, coworkers, type of work done, and communication within the organization). Suggestions have been proposed for educational managers to consider professional and personal perceptions related to Job Satisfaction based on Teacher's needs and perceptions.
\end{abstract}

Keywords: Job Satisfaction, Higher Education Institutions, Teachers, Private Universities, Public Universities, Pakistan.

\section{Introduction}

It is generally recognized that Job Satisfaction is a major determinant of employee and organizational performance and effectiveness in industrial and organizational settings (Laschinger, 2001; Riketta, 2002; Silvertone, 2014; Bhatti, Cheema, Shaikh, Syed \& Bashir, 2014; Asrar-ul-Haq, Kuchinke \& Iqbal, 2017). Job satisfaction, according to Green (2000), is a state of mind in which workers feel comfortable at their workplace without any internal or external disturbance, considered a smaller scale idea of life. As Belias and Koustelios (2014) have noted, "job satisfaction refers to the employees' perceptions of their working environment, relations with colleagues, institution aims and strategies and success criteria" (p. 132). In other terms, Job Satisfaction is associated with the worker's passionate reaction when their desires are taken into account (Sönmezer \& Eryaman, 2008). 
Within the university context, the importance of responding to the professional needs of workers has been recognized and studies have been conducted to analyze the conditions and factors involved in job satisfaction among teachers (Hina, Zamir, \& Nudrat, 2014; Mathur, \& Mehta, 2015; Pan, Shen, Liu, Yang, \& Wang, 2015; Hashim, Khattak, \& Kee, 2016; Adhikari, \& Barbhuiya, 2016; Alonderiene, \& Majauskaite, 2016; Stankovska, Angelkoska, Osmani, \& Grncarovska, 2017; Chipunza, \& Malo, 2017).

An in-depth literature review has been conducted based on teacher Job Satisfaction in a higher education context, from 2000 to 2018, revealing the following critical factors: recognition, growth, motivation, promotion opportunities, work-life balance, human relationships, benefits, rewards, working conditions, recognition, or organizational support. Some of the aspects highlight in the theoretical review are included in the Job Satisfaction Survey (JSS) Scale by Spector (1985, Spector, 1997) adapted for application to this empirical survey.

\section{Literature review}

\subsection{Factors affecting Job Satisfaction in Higher Education Institutions}

It is commonly believed that satisfied employees will not leave their organizations (Rahman, Rahman \& Ali, 2015). Rewards and trainings are prerequisites to create an appropriate institutional atmosphere in the professional public service that contributes to a performance evaluation system (Faizal, 2005). A study with Malaysian academics found positive effects of organizational support and person-job fit on career success (Said, Rasdi, Samah, Silong \& Sulaiman, 2015).

The following organizational variables affect teacher satisfaction and motivation, as seen in the literature review of 54 studies: climate, culture, and performance appraisal (Viseu, Neves, Rus, Canavarro \& Pereira, 2016). On the other hand, results from a study with Chinese university teachers $(n=1.210)$ indicate that improving the perceived organizational support may increase the level of job satisfaction for university teachers (Pan, Shen, Liu, Yang \& Wang, 2015). The Transformational Leadership style is one factor for the Job Satisfaction of the academic staff in public tertiary institutions (Ahmad, Bibi, \& Majid, 2017; Baron \& Greenberg, 2003; Alonderiene \& Majauskaite, 2016; Hashim, Khattak \& Kee, 2016).

Reasons for Job Satisfaction include achievement, recognition, responsibility, growth, and motivation in the job (Flowers \& Hughes, 1973), having a strong positive relationship with increased creativity and productivity (Catano, Darr \& Campbell, 2007). Factors that affect satisfaction or dissatisfaction at work for university teachers include job security (Oshagbemi, 1997) and sense of appreciation to develop one's identity (Lankveld, Schoonenboom, Volman, Croiset \& Beishuizen, 2017). Enhancing Job Satisfaction with work conditions can increase the degree of an employee's organizational commitment (Nawab \& Bhatti, 2011). Hence the importance of improving working conditions to increase organizational commitment (Nawab \& Bhatti, 2011).

Empirical evidence from private universities in Bangladesh concludes that working conditions (Masum, Azad \& Beh, 2015) are a determinant of Job Satisfaction in academics. As for teacher job stressors, the following should be considered: the absence of office facilities, excessive official paperwork (Tahseen, 2015) and a lack of opportunities for professional career development (Bhatti, Cheema, Shaikh, Syed \& Bashir, 2014; Tahseen, 2015; Adhikari \& Barbhuiya, 2016).

It is also important to note the value of human relationships as a positive effect on staff empowerment and commitment (Bendermacher, Egbrink, Wolfhagen, Leppink \& Dolmans, 2017), promoting the creation of teaching and learning communities in Higher Education Institutions. Other aspects that influence job satisfaction are training \& development, 
leadership or quality culture among academic staff (Ahmad, Bibi \& Majid, 2017; Bendermacher, Egbrink, Wolfhagen \& Dolmans, 2017).

Considering the personal context of the teachers, a study conducted with 424 academic and administrative employees from 25 public and private universities in the Bikaner district of Rajasthan, India, concluded that the work-life balance between the personal and professional life is a significant component that influenced job satisfaction (Mathur \& Mehta, 2015). These results coincide with those of Mudrak et al (2018) in the case of teachers from the Czech Republic $(n=2.071)$ who propose policies to promote the quality of academic leadership and the work-family balance for its beneficial effects.

An Exploratory Factor Analysis developed by Chauhan, Goel, \& Arora (2018), reveals the need to improve the motivation of faculty members in public and private universities, fostering policies that favor factors such: Growth Opportunities, Interpersonal Relationships, Participative Management, Job Security, Monetary Benefits or Research-based Activities.

Oshagbemi (2000) investigates the relationship between university teacher satisfaction and salary in the United Kingdom, showing that over $50 \%$ of the respondents were dissatisfied with their pay. Nevertheless, Adhikari \& Barbhuiya (2016) have found that teachers from the Public Assam University in India, are satisfied with 'Pay and Allowance'.

An outstanding contribution was made by Spector (1997), who considers Job Satisfaction as "the extent to which people like (satisfaction) or dislike (dissatisfaction) their jobs" (p. 2), validating the Job Satisfaction Survey (JSS) Scale including 9 facets: (1) pay and pay raises, (2) promotion opportunities, (3) person's immediate supervisor, (4) fringe benefits, (5) rewards (not necessarily monetary) given for good performance, (6) rules and procedures, (7) coworkers, (8) type of work done, and (9) communication within the organization. The comparison made in this study on the opinion of teachers regarding job satisfaction is based on the Spector Scale.

\subsection{Research on University Teacher Job Satisfaction in the context of Pakistan}

In this section, some studies on teacher job satisfaction in the context of public and private universities in Pakistan are presented. Some results reported strong correlations between Organizational Culture and Job Satisfaction of teachers of Lahore, Punjab (Sabri, Ilyas, \& Amjad, 2011), revealing satisfaction with coworker relations (Adhikari \& Barbhuiya, 2016; Chipunza \& Malo, 2017). Analysis of data from 125 full-time university teachers in Pakistan indicates that facets of job satisfaction (pay, promotion opportunities, coworkers, job security, training opportunities, and working conditions) were significantly related to teacher organizational commitment (Ali \& Zafar, 2006).

An initial block of studies focuses on the public sector, finding that variables such as work experience have an impact on teacher motivation, finding that those with less work experience being more extrinsically motivated (Ahluwalia \& Preet, 2017). Data collected from 406 teachers from public sector colleges in the Punjab, revealed that job satisfaction is largely caused by intrinsic motivational factors such as: opportunities to acquire new skills, promotion opportunities, participation in decision making, and autonomy, recognition (Nadim, Chaudhry, Kalyar, \& Riaz, 2012). Some job-related factors emerge from the qualitative research on teachers from the Public University of Punjab $(n=41)$ who participate in focus group discussions followed by in-depth interviews: satisfaction with the reward system, peers, and social environment (Sheikh, 2017). A study in the public sector shows that high perception of organizational support by university teachers promotes the reduction of job stressors and conflicts (Khurram, 2009). Findings from an exploratory study on teacher motivation in public sector higher educational institutions of Pakistan reveal some significant factors such as job design and working environment, performance management system, and training and development (Rasheed, Humayon, Awan, \& Ahmed, 2016). The study carried 
out by Amin, Shah, \& Tatlah (2013) in a public university in Punjab $(n=287)$ shows that the transformational leadership style of the director has a strong positive and statistically significant effect on the faculty's intrinsic, extrinsic and overall job satisfaction. However, the need to practice appropriate leadership style/s in different situations and even at different stages of the same situation is highlighted. Public university professors $(n=15)$ from Badin were surveyed and interviewed, revealing overall satisfaction with their jobs facets: interpersonal relations; freedom to ideate and act; job security and general working conditions (Bhatti, Cheema, Shaikh, Syed \& Bashir, 2014). Rahman et al (2015) validated the interdependence of employee development and commitment, Job Satisfaction, and their impact on intention to quit, as faculty members of the public sector universities in Khyber Pakhtunkhwa. A study with public university teachers $(n=341)$, shows that employee Job Satisfaction is influenced by factors such as job design, working environment, performance management system, and training and development (Rasheed, Humayon, Awan \& Ahmed, 2016).

Another block of studies focuses on the public and private sector in Pakistan, and the following variables were analyzed: working conditions, promotion opportunities, payment and benefits, job security and personal determinants.

A comparative study with 531 university teachers in Pakistan and Finland (Malik, Björkqvist \& Österman, 2017) found significantly better working conditions, social support at work and promotion opportunities in the Finnish sample as compared to the one from Pakistan. A study by Chughtai (2003) considering 45 colleges in Lahore (26 public and 19 private), analyzes the different variables related to satisfaction: college characteristics, teacher background, intrinsic factors (the teaching itself) and extrinsic factors (the teaching environment). Five hundred and two (502) teachers participated in the study (301 from public, and 201 from private sector) which found that achievement, recognition, and payment are determinant factors of Teacher Job Satisfaction. Results from a study on 17 public and private universities in Islamabad $(\mathrm{n}=10,223$ teachers) indicate that employee benefits account for $54 \%$ of the variation in Job Satisfaction (Hina, Zamir \& Nudrat, 2014).

A literature review examining Pakistani public and private universities reveals the need to enhance the research culture system between teachers and directors (Shabbir \& Khalid, 2016), even if the results from Blix, Cruise, Mitchell, \& Blix, (1994) show that research-related activities were more stressful than either teaching or service. Results of the study on Job Satisfaction for public and private universities teachers in Pakistan $(n=410)$ present a theoretical model of personal determinants of satisfaction, with full professor qualification, followed by assistant professors having the highest effect (Nas, 2016).

Findings from Khalid, Irshad, \& Mahmood (2012) examining university teachers from Punjab, indicate that private sector teachers were satisfied with their pay, supervision, and promotional opportunities. Data collected from 500 teachers from 5 private sector Higher Education Institutes of Punjab, showed that workplace friendship and informal relations have a positive function on Job Satisfaction and employee commitment (Amjad, Sabri, Ilyas, \& Hameed, 2015).

These aspects analyzed in the literature review affect job satisfaction, advancing in the overall development of the teaching, research and management functions of university faculty in the public and private sectors.

\section{Methodological approach}

\subsection{Research question}

The study's research question is: What is the perception of Job Satisfaction among teachers in public and private universities of Punjab, Pakistan? 


\subsection{Type of study}

A transversal, comparative study with two independent samples was conducted, following the survey method from a quantitative approach.

\subsection{Population and sample}

From a population of 38 universities in Punjab (17 from the private sector and 21 from the public sector) (Pakistan Statistical Bureau, 2016), 10 universities were selected (5 public and 5 private) from the Lahore division (Punjab, Pakistan), using the cluster sampling technique. Respondents were 345 teachers from three departments of social sciences (English, Islamic studies, and Education) (203 from public and 142 from private sectors) including Lecturers, Assistant and Associate Professors and Professors, using convenience sampling.

Public teachers designation is: lecturer (60.1\%), Assistant Professor (26.1\%), Associate Professor (8.9\%), and Professor (4.9\%). Their academic qualification is: M.A/M.Sc (43.3\%), M.Phil (19.7\%), Ph.D (30.5\%), and Any other (6.4\%). Teaching Experience is 1-5 years (28.6\%), 6-10 (34\%), 11-15 (20.2\%), 16-20 (13.8\%), and Above 20 (3.4\%).

Private teachers designation is: lecturer $(83.1 \%)$, Assistant Professor (12\%), Associate Professor $(2.1 \%)$, and Professor (2,8\%). Their academic qualification is: M.A/M.Sc $(62.7 \%)$, M.Phil (32.4\%), Ph.D (2.8\%), and Any other (2.1\%). Teaching Experience in years is: 1-5 (35.9\%), 6-10 (44.4\%), 11-15 (16.9\%), 16-20 (2.1\%), and Above 20 (0.7\%).

\subsection{Instrument}

A questionnaire was used for data collection on the Job Satisfaction of teachers from public and private universities (36 items). Data were collected upon visiting the selected universities, assuring the confidentiality of the data. A 5-point Likert scale was used in both questionnaires: Strongly Disagree $(\mathrm{SDA})=1$, Disagree $(\mathrm{DA})=2$, Undecided $(\mathrm{UD})=3$, Agree $(A)=4$, and Strongly Agree $(S A)=5$. The questionnaire was pilot tested on 20 teachers. Cronbach's alpha was calculated, obtaining a reliability of over .80 .

\section{Empirical results and discussion}

Results from a descriptive (percentages and median) and inferential analysis applying the Chi-Squared Test (X2-test) using SPSS (v.21) are presented. Application of the X2-test aims to determine whether the variables are independent or related. For those cases in which the test application requirements were not fulfilled, the assessment of significance was implemented using the exact Monte Carlo method.

Additional tests were also carried out (measures of association) to determine the strength of the relation, generally being moderate-low or low, and therefore, not included in the tables. In order to determine where the significant differences between surveyed participants from public and private universities take place, adjusted standardized residuals (ASRES) were analyzed. The ASRES "takes into account both the number of comparisons made and sample size and reports a more accurate difference between the observed and expected counts (...) and inform us of which cells are associated with statistically significant differences" (Meyers, Gamst \& Guarino, 2013, p. 670). Standardized residuals normalize data in chi square hypothesis testing. With a $95 \%$ confidence level, standardized residuals over 1.96 and 2.58 are considered significant. A Z score of over 1.96 is $\mathrm{p}<0.05$, and above 2.58 is $\mathrm{p}<0.01$.

The contingency tables featuring the teacher's university status and each item from the survey are presented below. Only results with significant differences have been included. 
Table 1. I feel I am being paid a fair amount for the work I do

\begin{tabular}{lcccccccc}
\hline Universities Status & SDA & DA & UD & A $^{* *}$ & SA* & N & Median & $\begin{array}{c}X^{2} \text {-test } \\
\text { (p-value, Monte Carlo) }\end{array}$ \\
\hline Public & $3.0 \%$ & $4.4 \%$ & $4.9 \%$ & $12.8 \%$ & $74.9 \%$ & 203 & 5 & 0.001 \\
Private & $1.4 \%$ & $7.7 \%$ & $1.4 \%$ & $27.5 \%$ & $62.0 \%$ & 142 & 5 & \\
\hline P & & & & & & &
\end{tabular}

$* p<0.05 * * p<0.01$

The result of the Chi-Squared test showed a significant relationship between the variables shown in the contingency table above $(\mathrm{X} 2(4, \mathrm{~N}=345)=16.94, \mathrm{p}=.001)$. The analysis of the adjusted standardized residuals revealed that the larger proportion of agreement among private university teachers (ASRES=3.4) and the proportion of strong agreement among public university teachers (ASRES=2.6) contributed to the significance of the results.

Table 2. I like the people I work with

\begin{tabular}{lcccccccc}
\hline Universities Status & SDA & DA & UD** & A & SA & N & Median & $X^{2}$-test $(\mathrm{p}$-value $)$ \\
\hline Public & $0 \%$ & $3.0 \%$ & $9.4 \%$ & $22.7 \%$ & $65.0 \%$ & 203 & 5 & 0.008 \\
Private & $1.4 \%$ & $5.6 \%$ & $1.4 \%$ & $20.4 \%$ & $71.1 \%$ & 142 & 5 & \\
\hline$* * p<0.01$ & & & & & & & &
\end{tabular}

The result of the Chi-Squared test showed a significant relationship between the variables shown in the contingency table above $(\mathrm{X} 2(4, \mathrm{~N}=345)=13.67, \mathrm{p}=.008)$. The analysis of the adjusted standardized residuals revealed that the larger proportion of undecided in the public university teachers (ASRES=3.0) contributed to the significance of the results.

Table 3. I sometimes feel my job is meaningless

\begin{tabular}{lcccccccc}
\hline Universities Status & SDA & DA & UD** & A & SA** & N & Median & $X^{2}$-test (p-value) \\
\hline Public & $11.8 \%$ & $26.6 \%$ & $31.0 \%$ & $13.3 \%$ & $17.2 \%$ & 203 & 3 & $<0.001$ \\
Private & $17.6 \%$ & $23.9 \%$ & $50.0 \%$ & $7.0 \%$ & $1.4 \%$ & 142 & 3 & \\
\hline
\end{tabular}

$* * p<0.01$

The result of the Chi-Squared test showed a significant relationship between the variables shown in the contingency table above $(\mathrm{X} 2(4, \mathrm{~N}=345)=35.52, \mathrm{p}<.001)$. The analysis of the adjusted standardized residuals (ASRES) revealed that the larger proportion of undecided among private university teachers (ASRES=3.6) and the proportion of strong agreement among public university teachers (ASRES=4.7) contributed to the significance of the results.

Table 4. Communication seems good within this organization

\begin{tabular}{lcrrrrrrc}
\hline Universities Status & SDA $^{*}$ & DA & UD & A* & SA & N & Median & $X^{2}$-test (p-value) \\
\hline Public & $0 \%$ & $8.9 \%$ & $7.9 \%$ & $25.6 \%$ & $57.6 \%$ & 203 & 5 & 0.022 \\
Private & $2.8 \%$ & $9.2 \%$ & $5.6 \%$ & $15.5 \%$ & $66.9 \%$ & 142 & 5 & \\
\hline
\end{tabular}

$* p<0.05$

The result of the Chi-Squared test showed a significant relationship between the variables shown in the contingency table above $(\mathrm{X} 2(4, \mathrm{~N}=345)=11.50, \mathrm{p}=.022)$. The analysis of the adjusted standardized residuals revealed that the larger proportion of disagreement 
among private university teachers $(\mathrm{ASRES}=2.4)$ and the proportion of agreement among public university teachers (ASRES=2.3) contributed to the significance of the results.

Table 5. Raises (increases in pay) are too few and far between

\begin{tabular}{lccrccccc}
\hline Universities Status & SDA & DA** $^{* *}$ & UD & $\mathrm{A}^{*}$ & SA** $^{* *}$ & $\mathrm{~N}$ & Median & $X^{2}$-test $(\mathrm{p}$-value) \\
\hline Public & $1.0 \%$ & $8.4 \%$ & $8.9 \%$ & $32.5 \%$ & $49.3 \%$ & 203 & 4 & 0.001 \\
Private & $2.8 \%$ & $1.4 \%$ & $8.5 \%$ & $20.4 \%$ & $66.9 \%$ & 142 & 5 & \\
\hline
\end{tabular}

$* p<0.05 * * p<0.01$

The result of the Chi-Squared test showed a significant relationship between the variables shown in the contingency table above $(\mathrm{X} 2(4, \mathrm{~N}=345)=18.03, \mathrm{p}=.001)$. The analysis of the adjusted standardized residuals revealed that the larger proportion of disagreement (ASRES=2.8) and agreement (ASRES=2.5) among public university teachers, along with the high proportion of strong disagreement among public university teachers (ASRES=3.3) contributed to the significance of the results.

Table 6. Those who do well on the job stand a fair chance of being promoted

\begin{tabular}{lcrcccccc}
\hline Universities Status & SDA & DA & UD & A $^{* *}$ & SA & N & Median & $X^{2}$-test (p-value) \\
\hline Public & $2.0 \%$ & $7.4 \%$ & $9.4 \%$ & $19.2 \%$ & $62.1 \%$ & 203 & 5 & 0.001 \\
Private & $5.6 \%$ & $9.2 \%$ & $16.2 \%$ & $4.9 \%$ & $64.1 \%$ & 142 & 5 & \\
\hline
\end{tabular}

$* * p<0.01$

The result of the Chi-Squared test showed a significant relationship between the variables shown in the contingency table above $(\mathrm{X} 2(4, \mathrm{~N}=345)=19.60, \mathrm{p}=.001)$. The analysis of the adjusted standardized residuals revealed that the larger proportion of agreement among public university teachers (ASRES=3.8) contributed to the significance of the results.

Table 7. The benefits received are as good as most other organizations offer

\begin{tabular}{lcccccccc}
\hline Universities Status & SDA $^{*}$ & DA & UD & A** $^{* *}$ & SA & N & Median & $X^{2}$-test (p-value) \\
\hline Public & $1.0 \%$ & $21.2 \%$ & $7.4 \%$ & $26.6 \%$ & $43.8 \%$ & 203 & 4 & 0.002 \\
Private & $4.2 \%$ & $26.1 \%$ & $9.9 \%$ & $10.6 \%$ & $49.3 \%$ & 142 & 4 & \\
\hline
\end{tabular}

$* p<0.05 * * p<0.01$

The result of the Chi-Squared test showed a significant relationship between the variables shown in the contingency table above $(\mathrm{X} 2(4, \mathrm{~N}=345)=16.53, \mathrm{p}=.002)$. The analysis of the adjusted standardized residuals revealed that the larger proportion of disagreement among private university teachers (ASRES $=2.0$ ) and the proportion of agreement among public university teachers (ASRES=3.7) contributed to the significance of the results.

Table 8. I find I have to work harder at my job because of the incompetence of people I work with

\begin{tabular}{lcccccccc}
\hline Universities Status & SDA** & DA & UD & A** & SA & N & Median & $X^{2}$-test (p-value) \\
\hline Public & $3.9 \%$ & $22.7 \%$ & $6.9 \%$ & $29.1 \%$ & $37.4 \%$ & 203 & 4 & $<0,001$ \\
Private & $16.2 \%$ & $22.5 \%$ & $11.3 \%$ & $5.6 \%$ & $44.4 \%$ & 142 & 4.5 & \\
\hline$* * p<0.01$ & & & & & & & &
\end{tabular}


The result of the Chi-Squared test showed a significant relationship between the variables shown in the contingency table above $(\mathrm{X} 2(4, \mathrm{~N}=345)=40.42, \mathrm{p}<.001)$. The analysis of the adjusted standardized residuals revealed that the larger proportion of disagreement among private university teachers (ASRES $=3.9$ ) and the proportion of agreement among public university teachers (ASRES=5.4) contributed to the significance of the results.

Table 9. I like doing the things I do at work

\begin{tabular}{lcccccccc}
\hline Universities Status & SDA & DA & UD $^{* *}$ & $\mathrm{~A}^{* *}$ & $\mathrm{SA}$ & $\mathrm{N}$ & Median & $X^{2}$-test (p-value) \\
\hline Public & $1.5 \%$ & $14.3 \%$ & $10.8 \%$ & $36.9 \%$ & $36.5 \%$ & 203 & 4 & $<0,001$ \\
Private & $0 \%$ & $18.3 \%$ & $23.2 \%$ & $19.0 \%$ & $39.4 \%$ & 142 & 3.5 & \\
\hline$* * p<0.01$ & & & & & & & &
\end{tabular}

The result of the Chi-Squared test showed a significant relationship between the variables shown in the contingency table above $(\mathrm{X} 2(4, \mathrm{~N}=345)=20.29, \mathrm{p}<.001)$. The analysis of the adjusted standardized residuals revealed that the larger proportion of undecided among private university teachers (ASRES=3.1) and the proportion of agreement among public university teachers (ASRES=3.6) contributed to the significance of the results.

Table 10. The goals of this organization are not clear to me

\begin{tabular}{lcrrrcccc}
\hline Universities Status & SDA & DA* & UD & A $^{* *}$ & SA & N & Median & $X^{2}$-test $(\mathrm{p}$-value) \\
\hline Public & $5.9 \%$ & $50.2 \%$ & $3.4 \%$ & $17.2 \%$ & $23.2 \%$ & 203 & 2 & 0.004 \\
Private & $5.6 \%$ & $64.1 \%$ & $7.0 \%$ & $5.6 \%$ & $17.6 \%$ & 142 & 2 & \\
\hline
\end{tabular}

$* p<0.05 * * p<0.01$

The result of the Chi-Squared test showed a significant relationship between the variables shown in the contingency table above $(\mathrm{X} 2(4, \mathrm{~N}=345)=15.33, \mathrm{p}=.004)$. The analysis of the adjusted standardized residuals revealed that the larger proportion of disagreement among private university teachers (ASRES $=2.5$ ) and the proportion of agreement among public university teachers (ASRES=3.2) contributed to the significance of the results.

Table 11. I feel unappreciated by the organization when I think about what they pay me

\begin{tabular}{lcccccccc}
\hline Universities Status & SDA & DA** & UD** & A** & SA & N & Median & $X^{2}$-test (p-value) \\
\hline Public & $7.9 \%$ & $20.2 \%$ & $33.0 \%$ & $18.7 \%$ & $20.2 \%$ & 203 & 3 & $<0.001$ \\
Private & $12.0 \%$ & $8.5 \%$ & $49.3 \%$ & $7.0 \%$ & $23.2 \%$ & 142 & 3 & \\
\hline$* * p<0.01$ & & & & & & & &
\end{tabular}

The result of the Chi-Squared test showed a significant relationship between the variables shown in the contingency table above $(\mathrm{X} 2(4, \mathrm{~N}=345)=23.10, \mathrm{p}<.001)$. The analysis of the adjusted standardized residuals revealed that the larger proportion of disagreement (ASRES=3.0) and agreement (ASRES=3.1) among public university teachers, as well as the larger proportion of undecided among public university teachers (ASRES=3.0) contributed to the significance of the results.

Table 12. There are few rewards for those who work here

\begin{tabular}{llrrrrrrr}
\hline Universities Status & SDA** $^{* *}$ & DA & UD & A** & SA** & N & Median & $X^{2}$-test $(\mathrm{p}$-value) \\
\hline Public & $0 \%$ & $9.4 \%$ & $5.9 \%$ & $39.9 \%$ & $44.8 \%$ & 203 & 4 & $<0.001$ \\
Private & $4.2 \%$ & $6.3 \%$ & $5.6 \%$ & $20.4 \%$ & $63.4 \%$ & 142 & 5 & \\
\hline$* * p<0.01$ & & & & & &
\end{tabular}


The result of the Chi-Squared test showed a significant relationship between the variables shown in the contingency table above $(\mathrm{X} 2(4, \mathrm{~N}=345)=24.95, \mathrm{p}<.001)$. The analysis of the adjusted standardized residuals revealed that the larger proportion of strong disagreement (ASRES=3.0) and strong agreement (ASRES=3.4) among private university teachers, as well as the larger proportion of agreement among public university teachers (ASRES=3.8) contributed to the significance of the results.

Table 13. I have too much to do at work

\begin{tabular}{lllrrrrrc}
\hline Universities Status & SDA & DA** & UD & A & SA** & N & Median & $X^{2}$-test $(\mathrm{p}$-value) \\
\hline Public & $1.0 \%$ & $12.3 \%$ & $3.9 \%$ & $16.3 \%$ & $66.5 \%$ & 203 & 5 & 0.001 \\
Private & $0 \%$ & $1.4 \%$ & $4.2 \%$ & $14.8 \%$ & $79.6 \%$ & 142 & 5 & \\
\hline$* * p<0.01$ & & & & & & & &
\end{tabular}

The result of the Chi-Squared test showed a significant relationship between the variables shown in the contingency table above $(\mathrm{X} 2(4, \mathrm{~N}=345)=16.22, \mathrm{p}=.001)$. The analysis of the adjusted standardized residuals revealed that the larger proportion of disagreement among public university teachers (ASRES $=3.7)$ and the proportion of strong agreement among private university teachers (ASRES=2.7) contributed to the significance of the results.

Table 14. I enjoy with my coworkers (colleagues)

\begin{tabular}{lcccccccc}
\hline Universities Status & SDA $^{*}$ & DA & UD & $\mathrm{A}^{* *}$ & SA $^{* *}$ & $\mathrm{~N}$ & Median & $X^{2}$-test (p-value) \\
\hline Public & $1 \%$ & $3 \%$ & $4.9 \%$ & $36 \%$ & $55.2 \%$ & 203 & 5 & $<0.001$ \\
Private & $4.2 \%$ & $5.6 \%$ & $5.6 \%$ & $11.3 \%$ & $73.2 \%$ & 142 & 5 & \\
\hline${ }^{*} p<0.05 * * p<0.01$ & & & & & & &
\end{tabular}

The result of the Chi-Squared test showed a significant relationship between the variables shown in the contingency table above $(\mathrm{X} 2(4, \mathrm{~N}=345)=29.45, \mathrm{p}<.001)$. The analysis of the adjusted standardized residuals revealed that the larger proportion of strong disagreement (ASRES=2.0) and strong agreement (ASRES=3.4) among private university teachers, as well as the larger proportion of agreement among public university teachers (ASRES=5.2) contributed to the significance of the results.

Table 15. I feel a sense of pride in doing my job

\begin{tabular}{llrrrrrrc}
\hline Universities Status & SDA & DA & UD & A** & SA** & N & Median & $X^{2}$-test (p-value) \\
\hline Public & $1.0 \%$ & $2.0 \%$ & $3.0 \%$ & $36.9 \%$ & $57.1 \%$ & 203 & 5 & 0.009 \\
Private & $0 \%$ & $4.2 \%$ & $2.8 \%$ & $21.1 \%$ & $71.8 \%$ & 142 & 5 & \\
\hline
\end{tabular}

$* * p<0.01$

The result of the Chi-Squared test showed a significant relationship between the variables shown in the contingency table above $(\mathrm{X} 2(4, \mathrm{~N}=345)=12.59, \mathrm{p}=.009)$. The analysis of the adjusted standardized residuals revealed that the larger proportion of agreement among public university teachers (ASRES=3.1) and the proportion of strong agreement among private university teachers (ASRES $=2.8$ ) contributed to the significance of the results. 
Table 16. I feel satisfied with the chances of salary increases

\begin{tabular}{lcccccccc}
\hline Universities Status & SDA $^{*}$ & DA & UD** & A* & SA & N & Median & $X^{2}$-test (p-value) \\
\hline Public & $0 \%$ & $7.4 \%$ & $9,9 \%$ & $21.7 \%$ & $61.1 \%$ & 203 & 5 & $<0,001$ \\
Private & $2.8 \%$ & $13.4 \%$ & $1.4 \%$ & $13.4 \%$ & $69.0 \%$ & 142 & 5 & \\
\hline
\end{tabular}

$* p<0.05 * * p<0.01$

The result of the Chi-Squared test showed a significant relationship between the variables shown in the contingency table above $(\mathrm{X} 2(4, \mathrm{~N}=345)=22.07, \mathrm{p}<.001)$. The analysis of the adjusted standardized residuals revealed that the larger proportion of strong disagreement among private university teachers (ASRES=2.4) and the proportion of undecided (3.3) and agreement (ASRES=2.0) among public university teachers contributed to the significance of the results.

Table 17. There are benefits we do not have which we should have

\begin{tabular}{llrrrrrrc}
\hline Universities Status & SDA $^{* *}$ & DA & UD & $\mathrm{A}^{* *}$ & SA & N & Median & $X^{2}$-test $(\mathrm{p}$-value $)$ \\
\hline Public & $0 \%$ & $4.4 \%$ & $6.9 \%$ & $31.0 \%$ & $57.6 \%$ & 203 & 5 & $<0,001$ \\
Private & $8.5 \%$ & $6.3 \%$ & $9.9 \%$ & $16.2 \%$ & $59.2 \%$ & 142 & 5 & \\
\hline$* * p<0.01$ & & & & & & &
\end{tabular}

The result of the Chi-Squared test showed a significant relationship between the variables shown in the contingency table above $(\mathrm{X} 2(4, \mathrm{~N}=345)=26.05, \mathrm{p}<.001)$. The analysis of the adjusted standardized residuals revealed that the larger proportion of disagreement among private university teachers (ASRES=4.2) and the proportion of agreement among public university teachers (ASRES=3.1) contributed to the significance of the results.

Table 18. I like my supervisor

\begin{tabular}{lccrrrrrc}
\hline Universities Status & SDA & DA* & UD & A** & SA** & N & Median & $X^{2}$-test $(\mathrm{p}$-value) \\
\hline Public & $5.9 \%$ & $2.0 \%$ & $5.9 \%$ & $33.5 \%$ & $52.7 \%$ & 203 & 5 & $<0,001$ \\
Private & $2.8 \%$ & $7.0 \%$ & $5.6 \%$ & $14.8 \%$ & $69.7 \%$ & 142 & 5 & \\
\hline
\end{tabular}

$* p<0.05 * * p<0.01$

The result of the Chi-Squared test showed a significant relationship between the variables shown in the contingency table above $(\mathrm{X} 2(4, \mathrm{~N}=345)=22.42, \mathrm{p}<.001)$. The analysis of the adjusted standardized residuals revealed that the larger proportion of disagreement (ASRES=2.3) and strong agreement (ASRES=3.2) among private university teachers, as well as the larger proportion of agreement among public university teachers (ASRES=3.9) contributed to the significance of the results.

Table 19. I am satisfied with chances for my promotion

\begin{tabular}{lcccccccc}
\hline Universities Status & SDA $^{* *}$ & DA & UD & A $^{* *}$ & SA $^{*}$ & $\mathrm{~N}$ & Median & $X^{2}$-test $(\mathrm{p}$-value) \\
\hline Public & $0 \%$ & $7.9 \%$ & $10.3 \%$ & $29.6 \%$ & $52.2 \%$ & 203 & 5 & $<0.001$ \\
Private & $4.2 \%$ & $9.2 \%$ & $14.8 \%$ & $8.5 \%$ & $63.4 \%$ & 142 & 5 & \\
\hline${ }^{*} p<0.05{ }^{* * p} p 0.01$ & & & & & & & &
\end{tabular}

The result of the Chi-Squared test showed a significant relationship between the variables shown in the contingency table above $(X 2(4, N=345)=29.76, p<.001)$. The analysis of the adjusted standardized residuals revealed that the larger proportion of strong 
disagreement (ASRES=3.0) and strong agreement (ASRES=2.1) among private university teachers, as well as the larger proportion of agreement among public university teachers (ASRES=4.7) contributed to the significance of the results.

Table 20. There are too much backbiting and fighting at work

\begin{tabular}{lcccccccc}
\hline Universities Status & SDA** & DA & UD & A** & SA* & N & Median & $X^{2}$-test (p-value) \\
\hline Public & $3.9 \%$ & $61.6 \%$ & $7.9 \%$ & $13.8 \%$ & $12.8 \%$ & 203 & 2 & $<0.001$ \\
Private & $14.8 \%$ & $69.0 \%$ & $8.5 \%$ & $2.1 \%$ & $5.6 \%$ & 142 & 2 & \\
\hline
\end{tabular}

$*_{p}<0.05 * * p<0.01$

The result of the Chi-Squared test showed a significant relationship between the variables shown in the contingency table above $(\mathrm{X} 2(4, \mathrm{~N}=345)=29.50, \mathrm{p}<.001)$. The analysis of the adjusted standardized residuals revealed that the larger proportion of strong disagreement among private university teachers (ASRES=3.6) and disagreement (ASRES=3.7) and strong agreement (ASRES=2.2) among public university teachers contributed to the significance of the results.

Table 21. My job is enjoyable

\begin{tabular}{lcccccccc}
\hline Universities Status & SDA & DA* $^{*}$ & UD & A** & SA & N & Median & $X^{2}$-test (p-value) \\
\hline Public & $0.5 \%$ & $1.5 \%$ & $3.4 \%$ & $32 \%$ & $62.6 \%$ & 203 & 5 & $<0.001$ \\
Private & $2.8 \%$ & $5.6 \%$ & $7.0 \%$ & $16.2 \%$ & $68.3 \%$ & 142 & 5 & \\
\hline
\end{tabular}

$* p<0.05 * * p<0.01$

The result of the Chi-Squared test showed a significant relationship between the variables shown in the contingency table above $(\mathrm{X} 2(4, \mathrm{~N}=345)=18.46, \mathrm{p}<.001)$. The analysis of the adjusted standardized residuals revealed that the larger proportion of disagreement among private university teachers (ASRES=2.2) and the proportion of agreement among public university teachers (ASRES=3.3) contributed to the significance of the results.

Table 22. People get ahead as fast here as they do in other places

\begin{tabular}{lcccccccc}
\hline Universities Status & SDA** $^{*}$ & DA & UD & A** & SA** & N & Median & $X^{2}$-test $(\mathrm{p}$-value $)$ \\
\hline Public & $2.0 \%$ & $15.8 \%$ & $9.9 \%$ & $28.1 \%$ & $44.3 \%$ & 203 & 5 & $<0,001$ \\
Private & $10.6 \%$ & $11.3 \%$ & $8.5 \%$ & $7.0 \%$ & $62.7 \%$ & 142 & 5 & \\
\hline
\end{tabular}

$* * p<0.01$

The result of the Chi-Squared test showed a significant relationship between the variables shown in the contingency table above $(\mathrm{X} 2(4, \mathrm{~N}=345)=37.05, \mathrm{p}<.001)$. The analysis of the adjusted standardized residuals revealed that the large proportion of strong disagreement (ASRES=3.4) and strong agreement (ASRES=3.4) among private university teachers, as well as the larger proportion of agreement among public university teachers (ASRES=4.9) contributed to the significance of the results.

Table 23. My supervisor shows too little interest in the feelings of subordinates

\begin{tabular}{lcccccccc}
\hline Universities Status & SDA** & DA & UD & $\mathrm{A}^{* *}$ & SA** & N & Median & $X^{2}$-test $(\mathrm{p}$-value $)$ \\
\hline Public & $4.9 \%$ & $19.2 \%$ & $5.4 \%$ & $23.2 \%$ & $47.3 \%$ & 203 & 5 & $<0,001$ \\
Private & $17.6 \%$ & $5.6 \%$ & $5.6 \%$ & $9.2 \%$ & $62.0 \%$ & 142 & 5 & \\
\hline$* * p<0.01$ & & & & & & & &
\end{tabular}


The result of the Chi-Squared test showed a significant relationship between the variables shown in the contingency table above $(\mathrm{X} 2(4, \mathrm{~N}=345)=37.75, \mathrm{p}<.001)$. The analysis of the adjusted standardized residuals revealed that the larger proportion of strong disagreement (ASRES=3.8) and strong agreement (ASRES=2.7) among private university teachers, as well as the larger proportion of disagreement (ASRES=3.6) and agreement (ASRES=3.4) among public university teachers contributed to the significance of the results.

\section{Conclusion}

After the comparative study conducted, it may be concluded that perception of Job Satisfaction among Teachers in public and private universities in Punjab, Pakistan, show statistically significant differences of opinion in items related to salary, promotion, benefits, coworkers, type of work carried out, and communication within the organization. The percentages observed in response to the teacher questionnaire for both university sectors revealed their job satisfaction with regards to their salaries, promotion opportunities, relationship with colleagues and professional identity.

Based on the results of the study, a view is offered on aspects of job satisfaction in which teachers coincide and differ. It is important to highlight that the two sectors of teachers (public and private) respond in a similar way, but differ in that some items are "strongly agree" and others only "agree", and therefore it is necessary to continue deepening in these nuances. In both sectors, teachers feel proud of the type of work they perform, to a greater extent in option "agree" in the public and in the "strongly agree" option in the private sector. However, they consider that they have too much work, being a significant difference with a greater percentage in the "strongly agree" option on the part of the professors of private universities (Tables 15 and 13).

Regarding salary satisfaction, both private and public sectors consider their salary to be fair, with a high percentage opting for the options "agree" + "strongly agree" (Table 1); however, there was a significant difference in the "agree" option, given the higher percentage from the private sector, and in the "strongly agree" option, with a significant difference in the public sector. As for promotion opportunities, the higher percentage opt for the options "agree" + "strongly agree" (Table 19), with a significant difference in the "agree" option occurring within the public sector. These are in line with results from a study carried out by Chughtai (2003) on job satisfaction of public and private university teachers in Lahore, Pakistan, which determined that the teachers from the two sectors were equally satisfied with the actual work that they performed, highlighting recognition and salary as key factors. These same results were obtained in the research carried out by Adhikari \& Barbhuiya (2016) with teachers from the public sector in India, declaring that they are satisfied with their salary.

Nevertheless, Oshagbemi (2000) found that over 50\% of the respondents were dissatisfied with their pay in the United Kingdom.

The perception of teacher satisfaction with coworker relations (Table 14) shows significant differences in the "agree" option within the public sector, and in the "strongly agree" option within the private sector.

Both sectors express their dissatisfaction on how few and far between their salary raises are (Table 5), with the "strongly agree" option being the one that contributes to the significant differences in the private sector. This dissatisfaction is also found for rewards (Table 12), with the "strongly agree" option being the one that contributes to the significant differences in the private sector.

On the other hand, in our study, teachers from the public sector consider that bureaucracy makes their university work more difficult as compared to those of the private sector. These results coincide with evidence on the importance of highly satisfied teachers sharing organizational values and norms (Rahman, 2012) and attempt to ensure that 
accountability does not distract teachers from basic academic and research functions (Carless, 2009).

As pointed out by some researchers, personal determinants influence Job Satisfaction in organizations (Amjad et al, 2015; Nas, 2016), as do a good atmosphere or workplace friendship, as mentioned in the results from Amjad et al (2015) in Pakistani Universities, or from Masum et al (2015) in private universities in Bangladesh.

Our research was carried out in order to understand some of the problems that higher education teachers face in the public and private sector, and to provide some helpful suggestions to assist educational administrators and policy makers in the professional design and development of programs, considering current needs. Educational managers have the responsibility to motivate, promote and retain teachers, and maintain equity in the universities (Stankovska, Angelkoska, Osmani \& Grncarovska, 2017). This study may also provide useful suggestions for universities as to how to make teachers more satisfied with their jobs and how to promote positive facets of Job Satisfaction and organizational commitment, avoiding adversely factors. Future research may rely on interviews and focus group to offer more information regarding Faculty Job Satisfaction and Organizational Culture in public and private universities in Pakistan.

\section{References}

Adhikari, K., \& Barbhuiya, J. H. (2016). Mapping job satisfaction of central university teachers. Splint International Journal of Professionals, 3(11), 45-51.

Ahluwalia, A.K. \& Preet, K. (2017). Work Motivation, Organizational Commitment and Locus of Control vis-a-vis Work Experience amongst University Teachers. SIBM Pune Research Journal, 14, 26-33. Retrieved from: http://samvad.sibmpune.edu.in/index.php/samvad/article/view/118113/82888

Ahmad, A., Bibi, P., \& Majid, A. (2017). The impact of training \& development and transformational leadership over organizational commitment among academic staff in public tertiary institutions: The buffering role of coworker support. International Journal of Economic Perspectives, 11(1), 417-432.

Ali, A. \& Zafar, S. (2006). Antecedents and Consequences of Organizational Commitment Among Pakistani University Teachers. Applied H.R.M. Research, 11(1), 39-64. Retrieved from: https://pdfs.semanticscholar.org/e161/535a799a2693d94b0497d7045 b0518a10bef.pdf

Alonderiene, R., \& Majauskaite, M. (2016). Leadership style and Job Satisfaction in higher education institutions. International Journal of Educational Management, 30(1), 140164. doi:10.1108/IJEM-08-2014-0106

Amin, M., Shah, S., \& Tatlah, I. A. (2013). Impact of Principals/Directors' Leadership Styles on Job Satisfaction of the Faculty Members: Perceptions of the Faculty Members in a Public University of Punjab, Pakistan. Journal of Research \& Reflections in Education (JRRE), 7(2), 97-112.

Amjad, Z., Sabri, P., Ilyas, M., \& Hameed, A. (2015). Informal relationships at workplace and employee performance: A study of employee's private higher education sector. Pakistan Journal of Commerce and Social Sciences, 9(1), 303-321.

Asrar-ul-Haq, M., Kuchinke, K.P., \&, Iqbal, A. (2017). The relationship between corporate social responsibility, Job Satisfaction, and organizational commitment: Case of 
Pakistani higher education. Journal of Cleaner Production, 142, 2352-2363. doi:10.1016/j.jclepro.2016.11.040

Baron, A.R. \& Greenberg, J. (2003). Organizational Behavior in Organization: Understanding and managing the human side of work. Canada: Prentice Hall.

Belias, D., \& Koustelios, A. (2014). Organizational Culture and job satisfaction: A review. International Review of Management and Marketing, 4(2), 132-149.

Bendermacher, G., Egbrink, M., Wolfhagen, I., Leppink, J. \& Dolmans, D. (2017). Reinforcing pillars for quality culture development: a path analytic model. Studies in Higher Education, 1-21. doi:10.1080/03075079.2017.1393060

Bendermacher, G., Egbrink, M., Wolfhagen, I. \& Dolmans, D. (2017). Unravelling quality culture in higher education: a realist review. Higher Education, 73(1), 39-60. doi:10.1007/s10734-015-9979-2

Bhatti, K., Cheema, F., Shaikh, A., Syed, N. A., \& Bashir, R. (2014). Faceted and overall job satisfaction among university teachers: A case study of Laar Campus, Sindh University, Pakistan. Global Management Journal for Academic \& Corporate Studies, 4(2), $137-$ 146.

Blix, A., Cruise, R., Mitchell, B., \& Blix, G. (1994). Occupational stress among university Teachers. Educational research, 36(2), 157-169. doi:10.1080/0013188940360205

Carless, D. (2009). Trust, distrust and their impact on assessment reform. Assessment \& Evaluation in Higher Education, 34, 79-89. doi:10.1080/02602930801895786

Catano, V. M., Darr, W., \& Campbell, C. A. (2007). Performance appraisal of behavior based competencies: A reliable and valid procedure. Personnel Psychology, 60(1), 201-230

Chauhan, A., Goel, M., \& Arora, R. G. (2018). Motivation among Higher Education Academicians: A Factor Analytical Approach. ANVESHAK-International Journal of Management, 7(1), 172-189. doi:10.15410/aijm/2018/v7i1/119884

Chipunza, C., \& Malo, B. (2017). Organizational Culture and Job Satisfaction among academic professionals at a South African University of Technology. Problems and Perspectives in Management, 15(2), 148-161. doi:10.21511/ppm.15(2).2017.14

Chughtai, A. (2003). A Comparative Analysis of Job Satisfaction Among Public and Private Sector College/University Teachers in Lahore. Lahore Journal of Economics, 8(1), 91118. Retrieved from: http://121.52.153.179/JOURNAL/vol8-No1/Amir-final.pdf

Faizal, M. (2005). Institutionalization of performance appraisal system: a case study of the Maldivian public service. MS Thesis, University of Bergen, Norway.

Flowers, V.S. \& Hughes, Ch. L. (1973). Why Employees Stay. Harvard Business Review, 7, 1-20. Retrieved from: https://hbr.org/1973/07/why-employees-stay.

Green, J. (2000). Job Satisfaction of community college chairpersons. Unpublished PhD thesis Virginia Tech and State University.

Hashim, M., Khattak, M.A., \& Kee, D. (2016). Impact of Servant Leadership on Job Satisfaction: A Study of Teaching Faculty in Universities of Peshawar. Abasyn Journal of Social Sciences, Special Issue, AIC 2016, 312-320.

Hina, Q., Zamir, Sh., \& Nudrat, S. (2014). Impact of employee benefits on Job Satisfaction of Teachers at higher level. Journal of Education and Practice, 5(7), 122-129.

Khalid, S., Irshad, M.Z. \& Mahmood, B. (2012). Job Satisfaction among academic staff: A comparative analysis between public and private sector universities of Punjab, Pakistan. International Journal of Business and Management, 7(1), 126-136. 
Khurram, S. (2009). Perceived organizational support, antecedents and consequences proposing and testing a model in a public sector university of Pakistan. South Asian Journal of Management, 16(1), 7-26.

Lankveld, T., Schoonenboom, J., Volman, M., Croiset, G. \& Beishuizen, J. (2017). Developing a teacher identity in the university context: a systematic review of the literature. Higher Education Research \& Development, 36(2), 325-342. doi:10.1080/07294360.2016.1208154

Laschinger, H. (2001). The impact of workplace commitment, organizational trust on staff nurses' work satisfaction and organizational commitment. Health Care Management Review, 26(3), 7-24.

Malik, N.Q., Björkqvist, K., \& Österman, K. (2017). Factors Associated with Occupational Stress among University Teachers in Pakistan and Finland. Journal of Educational, Health and Community Psychology, 6(2), 1-14.

Masum, A., Azad, A., \& Beh, L. (2015). Determinants of academics' Job Satisfaction: Empirical evidence from private universities in Bangladesh: E0117834. PLoS One, 10(2). doi:10.1371/journal.pone.0117834

Mathur, A., \& Mehta, A. (2015). Factors affecting job satisfaction among employees of higher education: A case study. Journal of Strategic Human Resource Management, 4(1), 49-64. doi:10.21863/jshrm/2015.4.1.006

Meyers, L. C., Gamst, G., \& Guarino, A. J. (2013). Performing data analysis using IBM SPSS. Hoboken, New Jersey: Willey.

Mudrak, J., Zabrodska, K., Kveton, P., Jelinek, M., Blatny, M., Solcova, I., \& Machovcova, K. (2018). Occupational well-being among university faculty: A job demands-resources model. Research in Higher Education, 59(3), 325-348. doi:10.1007/s11162-017-9467-x

Nadim, M., Chaudhry, M. S., Kalyar, M. N., \& Riaz, T. (2012). Effects of motivational factors on teachers' job satisfaction: A study on public sector degree colleges of Punjab, Pakistan. The Journal of Commerce, 4(4), 25-32.

Nas, Z. (2016). The effects of personal determinants on Job Satisfaction of public and private universities' academicians in Pakistan. City University Research Journal, 6(2), 217-228. Retrieved from: http://www.cityuniversity.edu.pk/curj/Journals/Journal/jul\% 202016/02.pdf

Nawab, S., \& Bhatti, K. K. (2011). Influence of employee compensation on organizational commitment and job satisfaction: A case study of educational sector of Pakistan. International Journal of Business and Social Science, 2(8), 25-32. Retrieved from: http://www.ijbssnet.com/journals/Vol._2_No._8\%3B_May_2011/3.pdf

Oshagbemi, T. (1997). Job Satisfaction and dissatisfaction in Higher Education. Education + Training, 39(9), 354-359. doi:10.1108/00400919710192395

Oshagbemi, T. (2000). Correlates of pay satisfaction in higher education. International Journal of Educational Management, 14(1), 31-39. doi:10.1108/09513540010310387

Pan, B., Shen, X., Liu, L., Yang, Y., \& Wang, L. (2015). Factors associated with job satisfaction among university teachers in northeastern region of China: A crosssectional study. International Journal of Environmental Research and Public Health, 12(10), 12761-12775. doi:10.3390/ijerph121012761

Rahman, W. (2012). The Relationship of Attitudinal and Behavioural Outcomes with Employee Development in the Context of Performance Appraisal in Public Universities 
of Khyber Pakhtunkhwa. PhD Thesis, National University of Modern Languages, Islamabad.

Rahman, W., Rahman, H., \& Ali, F. (2015). Interrelationship of employee development, Organizational commitment, Job Satisfaction and their impact on turnover intentions. City University Research Journal, 5(2), 301-314.

Rasheed, M. I., Humayon, A. A., Awan, U., \& Ahmed, A. U. D. (2016). Factors affecting teachers' motivation: An HRM challenge for public sector higher educational institutions of Pakistan (HEIs). International Journal of Educational Management, 30(1), 101-114. doi:10.1108/IJEM-04-2014-0057

Riketta, M. (2002). Attitudinal organizational commitment and job performance: a metaanalysis. Journal of Organizational Behavior, 23, 257-66.

Sabri, P., Ilyas, M., \& Amjad, Z. (2011). Organizational Culture and Its Impact on the Job Satisfaction of the University Teachers of Lahore. International Journal of Business and Social Science, 2(24), 121-128. Retrieved from: http://ijbssnet.com/journals/Vol_2_No_24_Special_Issue_December_2011/13.pdf

Said, A., Rasdi, R., Samah, B., Silong, A., \& Sulaiman, S. (2015). A career success model for academics at Malaysian research universities. European Journal of Training and Development, 39(9), 815-835.

Shabbir, M., \& Khalid, M. I. (2016). Humanizing research culture system through quality assurance practices in the universities of Pakistan. Bulletin of Education and Research, 38(1), 235-250. Retrieved from: http://pu.edu.pk/images/journal/ier/PDFFILES/16_Shabbir\%20\&\%20Ibrahim_v38_1_2016.pdf

Sheikh, L. (2017). Antecedents and consequences of organizational commitment of teachers: case of University of the Punjab. Pakistan Economic and Social Review, 55(2), 363386.

Silverthorne, C. (2004). The impact of Organizational Culture and person-organization fit on organizational commitment and job satisfaction in Taiwan. Leadership \& Organization Development Journal, 25(7), 592-599. doi:10.1108/01437730410561477

Sönmezer, M. \& Eryaman, M. (2008). Comparative Analysis of Job Satisfaction Level of Public and Private School Teachers. Journal of theory and practice in education, 4(2), 189-212.

Spector, P. (1997). Job satisfaction: Application, assessment, causes, and consequences. London: Sage publications.

Stankovska, G., Angelkoska, S., Osmani, F., \& Grncarovska, S. (2017). Job Motivation and Job Satisfaction among Academic Staff in Higher Education. 15th Annual International Conference of the Bulgarian Comparative Education Society. Bulgaria, Jun 2017.

Tahseen, N. (2015). Work-related stress among teacher-educators: Evidence from Punjab. Pakistan Journal of Psychological Research, 30(2), 357.

Viseu, J., Neves, S., Rus, C., Canavarro, J., \& Pereira, J. (2016). Relationship Between Teacher motivation and organizational variables: A Literature review. Paideía, 26(63), 111-120. doi:10.1590/1982-43272663201613 